\title{
Metabolic Parameter and Insulin Resistance in Non Alcoholic Fatty Liver Disease Patient Attending Tertiary Care Hospital Coastal Andhra Pradesh
}

\author{
P.V.V. Satyanarayana ${ }^{1}$, M. Deepak Phanindra², Anand Acharya ${ }^{3}$ \\ ${ }^{1}$ Associate Professor, Department of General Medicine Konaseema Institute of Medical Science, Amalapuram, Andhra \\ Pradesh, ${ }^{2}$ Assistant Professor, Department of General Medicine Konaseema Institute of Medical Science, Amalapuram, \\ Andhra Pradesh, ${ }^{3}$ Professor of Pharmacology Konaseema Institute of Medical Science Amalapuram, Andhra Pradesh, India
}

Corresponding author: Dr. M. Deepak Phanindra, Assistant Professor, Department of General Medicine Konaseema Institute of Medical Science Amalapuram, Andhra Pradesh, India

DOI: http://dx.doi.org/10.21276/ijcmsr.2019.4.4.44

How to cite this article: P.V.V. Satyanarayana, M. Deepak Phanindra, Anand Acharya. Metabolic parameter and insulin resistance in non alcoholic fatty liver disease patient attending tertiary care hospital coastal Andhra Pradesh. International Journal of Contemporary Medicine Surgery and Radiology. 2019;4(4):D184-D187.

\section{A B S T R A C T}

Introduction: It has been reported that there are various metabolic abnormalities, obesity and type-2 DM associated with NAFLD in western world but there are very few study on metabolic parameters and insulin resistance associated with NAFLD in India. So this study was designed with an aim to determine the presence of component of metabolic syndrome and insulin resistance in non alcoholic fatty liver disease.

Material and methods: 150 patients were included in this study based on inclusion and exclusion criteria. Detail history of the patients were noted that includes drug history, patients were examined for evidence of clinical manifestation of chronic liver disease body mass index and all other metabolic parameters of all patients were measured.

Result: The mean of fasting insulin concentration was $9.156 \pm 1.6 \mathrm{ulU} / \mathrm{ml}$ in group A and5.94 $\pm 1.364 \mathrm{ulU} / \mathrm{ml}$ in group B. The $P$ value was 0.0026 . The mean value of HOMA-IR was $2.18 \pm 0.26$ in group A and $1.3836 \pm 0.44$ in group B. This difference is statically significant as $P$ value is 0.0001 .

Conclusion: To conclude most of the patient with NAFLD were obese but some having normal body weight also. Patients with NAFLD have higher FPG, dyslipidemia, fasting insulin concentration and HOMA-IR even though they are not diabetic. So insulin resistance, obesity, lipotoxicity and environmental factor are of major concern in development of non alcoholic fatty liver disease.

Keyword: NAFLD, Insulin Resistance, Dyslipidemia

\section{INTRODUCTION}

It has been reported that non alcoholic fatty liver disease is most common liver disease and its prevalence ranges from $20 \%$ to $30 \%$ in western world. ${ }^{1}$ The frequency of this disease varies with ethnicity. ${ }^{2}$ The prevalence of non alcoholic fatty liver disease is also high in Indian sub continent here it ranges from $4 \%$ to $29 \%$, which similar to western world. ${ }^{3,4}$ Non alcoholic fatty liver is defined as abnormality of the liver in the absence of alcohol consumption and presence of $\geq 5 \%$ hepatic steatosis in the absence of competing liver disease. ${ }^{5}$ Lonardo A et la in his review has concluded that non alcoholic fatty liver disease is considered to be both consequences and cause of metabolic syndrome. It's link with metabolic syndrome is more complex. ${ }^{6}$ Pathogenesis of NAFLD is complex it starts with hepatic triglyceride accumulation or steatosis, insulin resistance, proceed to steatohepatitis / inflammation, increased level of hepatic expression of inflammatory cytokines, decreased level of adeponektin, oxidative stress, mitochondrial and endoplasmic reticulum dysfunction, followed by fibrosis, genetic predisposition also play a role. J.K. Dowman et al. ${ }^{7}$ It has been reported that there are various metabolic abnormalities, obesity and type-2 DM associated with NAFLD in western world but there are very few study on metabolic parameters and insulin resistance associated with NAFLD in India. ${ }^{8}$ So this prospective was designed with an aim to determine the presence of component of metabolic syndrome and insulin resistance in non alcoholic fatty liver disease.

\section{MATERIAL AND METHODS}

This was a prospective observational and quantitative study, conducted in the department of general medicine Konaseema Institute of Medical Sciences from Jan 2018 to August 2019.

Selection of the patients: Based on exclusion and inclusion criteria, patients who underwent ultrasonography of abdomen for liver function test abnormality, or any other indication were enrolled for this study. 


\begin{tabular}{|l|l|}
\hline Exclusion criteria & Inclusion criteria \\
\hline Age more than 35 years & Diabetes mellitus \\
\hline Both sex & $\begin{array}{l}\text { Any disease of liver infec- } \\
\text { tive or autoimmune }\end{array}$ \\
\hline $\begin{array}{l}\text { NAFLD diagnosed by } \\
\text { USG }\end{array}$ & $\begin{array}{l}\text { Steatogenic drug, Alco- } \\
\text { holic }\end{array}$ \\
\hline
\end{tabular}

Sample size: Based on prevalence of NAFLD and confidence interval of $95 \%$, sample size was calculated to 149 , so 150 patients were included for this study. ${ }^{9}$

Ethics: Before start of the study permission of institutional ethics committee was obtained. Informed consent was obtained from all patients enrolled in this study.

Methods: 150 patients were included in this study based on inclusion and exclusion criteria. Detail history of the patients were noted that includes drug history, patients were examined for evidence of clinical manifestation of chronic liver disease body mass index of all patients were measured waist circumference was calculated. Various biochemical parameters like fasting plasma glucose and post prandial plasma glucose was measured by glucose oxidise peroxidise method.For total cholesterol, we used Liebermann-Burchard reaction colorimetric method; triglyceride was estimated by method of Neri and Fringe. HDL concentration was estimated by precipitation method. LDL concentration was calculated by WHO formula, LDL- cholesterol= total cholesterol- TG/5 - HDL (mg/dL). Plasma insulin was determined by using enzyme-linked immunosorbent assay. HOMA-IR was calculated by using this formula (FPI X FPG) $/ 22.5 .{ }^{10}$ Value more than 1.64 was considered insulin resistance.

Study designs: Patients selected as per exclusion and inclusion criteria were kept in Group A, in Group B 150 apparently healthy patients without NAFLD and diabetes mellitus were taken as control.

\section{STATISTICAL ANALYSIS}

Data was collected on Microsoft excel sheet and analysis was done by using mean, proportion chi square test and unpaired t-test was used, $\mathrm{P}$-value less than 0.05 was taken significant.

\section{RESULT}

As per exclusion and inclusion criteria, 150 patients diagnosed to be NAFLD were included in this study, kept in group $A$ and another 150 apparently healthy patients were selected as control and kept in group B.

As per table- 1 mean age of the patients in group $A$ was $45.525 \pm 9.041 \mathrm{yrs}$ and in centro group B it was $42.675 \pm 7.86 y$ rs. The $\mathrm{P}$-value was 0.70 which is more than 0.05 not significant statistically. Regarding comparison of sex ratio between two groups in group A M:F was 110:40 and in group $\mathrm{B}$ it was $108: 42$. The $\mathrm{P}$ value 0.89629 which was not significant statistically.Out of 150 patients in group A 16 were having normal body weight, 44 were overweight and 80 were obese but in group B, 32 having normal body weight, 64 were overweight and 54 were obese. So there is significant difference between two groups with respect to body mass index as $\mathrm{P}$ value was 0.001 . Mean of waist circumference was $94.62 \pm 6.421 \mathrm{~cm}$ in group $\mathrm{A}$ and $86.374+3.74 \mathrm{~cm}$ in group B.This difference was significant statistically.

From table-2 it is clear that mean of FPG was $91.42 \pm 6.424$ $\mathrm{mg} / \mathrm{dl}$ in group A and $76.324 \pm 4.376 \mathrm{mg} / \mathrm{dl}$ in group B. FPG was significant towards higher side in group $\mathrm{A}$. The $\mathrm{P}$ value was 0.00214 .

The mean of post prandial plasma glucose was $126.337 \pm 8.426$ $\mathrm{mg} / \mathrm{dl}$ in group A and $112.734 \pm 7.77 \mathrm{mg} / \mathrm{dl}$ in group B. The $\mathrm{P}$-value was 0.001 which is highly significant. The mean of

\begin{tabular}{|c|c|c|c|c|}
\hline \multicolumn{2}{|l|}{ Variables } & Group A (Mean \pm SD) & Group B (Mean \pm SD) & P value \\
\hline \multicolumn{2}{|l|}{ Age } & $45.525 \pm 9.041$ & $42.675 \pm 7.86$ & 0.707 \\
\hline \multirow[t]{2}{*}{ Sex } & $\mathrm{M}$ & 110 & 108 & \multirow[t]{2}{*}{.89629} \\
\hline & $\mathrm{F}$ & 40 & 42 & \\
\hline \multirow[t]{3}{*}{$\mathrm{BMI}(\mathrm{kg} / \mathrm{m} 2$} & Normal (18.5 to 22.9 ) & 16 & 32 & \multirow[t]{3}{*}{0.001032} \\
\hline & Over weight (23.0 to 24.9 ) & 44 & 64 & \\
\hline & Obese (25 and above) & 80 & 54 & \\
\hline \multicolumn{2}{|c|}{ Waist circumference } & $94.62 \pm 6.421$ & $86.374 \pm 3.74$ & 0.0262 \\
\hline
\end{tabular}

\begin{tabular}{|l|c|c|c|}
\hline Variables & Group A(Mean \pm SD) & Group B(Mean \pm SD) & P value \\
\hline FPG $(\mathrm{mg} / \mathrm{dl})$ & $91.42 \pm 6.424$ & $76.324 \pm 4.376$ & 0.002 \\
\hline PPPG $(\mathrm{mg} / \mathrm{dl})$ & $126.337 \pm 8.426$ & $112.734 \pm 7.7$ & 0.0001 \\
\hline TChol(mg/dl) & $218.64 \pm 26.34$ & $162.67 \pm 24.336$ & 0.0001 \\
\hline $\mathrm{LDL}(\mathrm{mg} / \mathrm{dl})$ & $148.90 \pm 30.46$ & $116.98 \pm 22.32$ & 0.001 \\
\hline $\mathrm{HDL}(\mathrm{mg} / \mathrm{dl})$ & $36.42 \pm 6.376$ & $39.47 \pm 9.32$ & 0.124 \\
\hline Tg(mg/dl) & $162.89 \pm 29.48$ & $116.42 \pm 20.96$ & 0.001 \\
\hline Fasting insulin conc(ulU/ml) & $9.156 \pm 1.6$ & $5.94 \pm 1.364$ & 0.0026 \\
\hline HOMA-IR & $2.18 \pm .26$ & $1.3836 \pm 0.44$ & 0.0001 \\
\hline AST & $68.26 \pm 18.42$ & $28.84 \pm 12.42$ & 0.001 \\
\hline ALT & $59.22 \pm 14.22$ & $24.12 \pm 14.62$ & 0.001 \\
\hline \multicolumn{2}{|c|}{ Table-2: Metabolic Parameters in both groups } & \\
\hline
\end{tabular}


total cholesterol in group A was $218.64 \pm 26.34 \mathrm{mg} / \mathrm{dl}$ and in group B it was $162.67 \pm 24.336 \mathrm{mg} / \mathrm{dl}$. These two value were statistically different as $\mathrm{P}$ value of 0.0001 . In group $\mathrm{A}$ the mean of LDL concentration was $148.90 \pm 30.46 \mathrm{mg} / \mathrm{dl}$ and in group B it was $116.98 \pm 22.32 \mathrm{mg} / \mathrm{dl}$, the $\mathrm{P}$ value was 0.001 . The mean of HDL concentration was $36.42 \pm 6.376 \mathrm{mg} / \mathrm{dl}$ in group A and $39.429 .32 \mathrm{mg} / \mathrm{dl}$ in group B which was not significant as $\mathrm{P}$ value was 0.124 . Triglyceride concentration was $162.89 \pm 29.48 \mathrm{mg} / \mathrm{dl}$ in group A and $116.42 \pm 2096 \mathrm{mg} /$ $\mathrm{d}$ l in group $\mathrm{B}$, the $\mathrm{P}$ value was 0.001 . The mean of fasting insulin concentration was $9.156 \pm 1.6 \mathrm{uIU} / \mathrm{ml}$ in group $\mathrm{A}$ and5.94 $\pm 1.364 \mathrm{uIU} / \mathrm{ml}$ in group $\mathrm{B}$. The $\mathrm{P}$ value was 0.0026 . The mean value of HOMA-IR was $2.18 \pm 0.26$ in group A and $1.3836 \pm 0.44$ in group $\mathrm{B}$. This difference is statically significant as $\mathrm{P}$ value is 0.0001 . The mean of AST was $68.26 \pm 18.42$ unit/litre in group $\mathrm{A}$ and $28.84 \pm 12.42$ unit/ litre in group $\mathrm{B}$. The $\mathrm{P}$ value was 0.001 . In group $\mathrm{A}$ the mean of ALT was $59.22 \pm 14.22 \mathrm{U} / \mathrm{Lt}$ and it group B it was $24.12 \pm 14.62 \mathrm{U} / \mathrm{Lt}$, the $\mathrm{P}$ value was 0.001 .

\section{DISCUSSION}

In present study we have evaluated the metabolic parameters and insulin resistance in 150 diagnosed cases of non alcoholic fatty liver diseases. In our study we have found that mean age of the patient was $45.525 \pm 9.041$ yrs, Sangeetha Suresh et al has reported that majority of subject were between 41 to 50 yrs of age which support our study. ${ }^{11} \mathrm{My}$ observation also corroborates with the finding of Kalra $\mathrm{S}$ et al. ${ }^{12}$ There is male predominance in our study, which is supported by the finding of Permpail BJ et al. ${ }^{13}$ We have observed in our study that $53.4 \%$ patient with NAFLD were obese, $26.6 \%$ were overweight, but in control group only $36 \%$ were obese and $42 \%$ were overweight, so obesity is associated with NAFLD. We have also observed that increased waist circumference is also strongly associated with NAFLD. This finding corroborates with the observation of Perumpail BJ et al, Majumdar A et al and Farrel GL et al. ${ }^{13,14,15}$

Regarding various metabolic parameters, we have observed that fasting plasma glucose was significantly high in NAFLD patients than control $(\mathrm{P}=0.00214,0.001)$. This finding is supported by the work of NovaKovicT et $\mathrm{al}^{16}$ and Pardhe B.D et al. ${ }^{17}$ Total serum cholesterol was significantly higher $(218.46 \pm 26.426$ vs $162.67 \pm 24.336)$ in NAFLD group than the control group $(\mathrm{P}=0.0001)$. This finding is supported by the steedy of Agarwal AK et $\mathrm{al}^{18}$ and D Mahling DV et al. ${ }^{19}$ In our study HDL level was low in NAFLD group in comparison to control $(36.42 \pm 6.376 \mathrm{mg} / \mathrm{dl}$ vs $39.97 \pm 9.32)$ which is supported by the work of Agrawal R et al. ${ }^{20} \mathrm{We}$ have observed that there is hypertriglyceridemia and LDL level was also high. Accumulation of triglyceride in hepatocytes is considered the main pathogenic trigger in the process of pathogenesis of NAFLD, various author has concluded that patients with NAFLD has disrupted lipid profile. ${ }^{21,22}$ Result of our study goes along with that.

In our study fasting insulin concentration and HOMA-IR are significantly higher in NAFLD group. The study group has significantly higher fasting insulin concentration then control $(9.15 \pm 1.6$ vs $5.94 \pm 1.364)$ and HOMA IR value was $(2.18 \pm 0.26$ vs $1.38 \pm 0.44)$ also high. So patients with NAFLD have higher FPG,fasting insulin conc and HOMA-IR even though they are not diabetic. This finding corroborates with the finding of Salgado et al. ${ }^{23}$

We have observed that both AST and ALT were significantly higher in NAFLD group than control group. This finding corroborates with the finding of NovaKovic et al. ${ }^{16}$

\section{CONCLUSION}

To conclude most of the patient with NAFLD were obese but some having normal body weight also. Patients with NAFLD have higher FPG, dyslipidemia, fasting insulin concentration and HOMA-IR even though they are not diabetic. So insulin resistance, obesity, lipotoxicity and environmental factor are of major concern in development of non alcoholic fatty liver disease.

\section{BIBLIOGRAPHY}

1. Younossi ZM, Koenig AB, Abdelatif D, Fazel Y, Henry L, Wymer M, Global epidemiology of nonalcoholic fatty liver disease-Meta-analytic assessment of prevalence, incidence, and outcomes.Hepatology. 2016; 64(2): 73-84

2. Browning, J. D. et al. Prevalence of hepatic steatosis in an urban population in the United States: impact of ethnicity. Hepatology 2004;40(4):1387-1395.

3. Amarapurkar D, Kamani P, Patel N, Gupte P, Kumar $\mathrm{P}$, Agal S, et al. Prevalence of non-alcoholic fatty liver disease: Population based study. Ann Hepatol. 2007;6(4):161-3.

4. Duseja A. Nonalcoholic fatty liver disease in India A lot done, yet more required! Indian J Gastroenterol 2010; 29(4):217-25.

5. Zobair M. Younossi, Aaron B. Koenig, Dinan Abdelatif, Yousef Fazel, Linda Henry, and Mark Wymer. Global Epidemiology of Nonalcoholic Fatty Liver DiseaseMeta-Analytic Assessment of Prevalence, Incidence, and Outcomes Hepatology 2016;64(1).

6. Lonardo A, Nascimbeni F, Mantovani A, Targher G. Hypertension, diabetes, atherosclerosis and NASH: cause or consequence? J Hepatol. 2018;68(2):335-52.

7. J. K. Dowman, J.W. Tomlinson and P.N. Newsome, Pathogenesis of non-alcoholic fatty liver diseaseJ. QJ Med 2010; 103(3):71-83

8. Hedley AA, Ogden CL, Johnson CL, Carroll MD, Curtin LF,Flegal KM. Prevalence of overweight and obesity among US,children, adolescents, and adults, 1999-2002. JAMA. 2004;291(2):2847-50.

9. Sample size to estimate a proportion or apparent prevalence with specified precision http://epitools. ausvet.com.au/content.php?page $=1$ Proportion

10. Banora E, Targher G, Alberiche M, Bonadonna RC, Saggiani F,Zenere MB, et al. Homeostasis model assessment closely mirrorsthe glucose clamp technique in the assessment of insulin sensitivity: studies in subjects with various degrees of glucose tolerance and insulin sensitivity. Diabetes Care. 2000;23(4):57-63.

11. Suresh S, Rajanbabu B, Veetil VM, Hussain A, Veetil JN.A study on the altered glycemic and lipid parameters and prevalence of insulin resistance in nonalcoholic fatty liver disease. J Family Med Prim Care. 2018;7(1):93-97.

12. Kalra S, Vithalani M, Gulati G, Kulkarni CM, Kadam 
Y, Pallivathukkal J, Das B, Sahay R, Modi KD. Study of prevalence of nonalcoholic fatty liver disease (NAFLD) in type 2 diabetes patients in India (SPRINT).J Assoc Physicians India. 2013;61(7):448-53

13. Perumpail BJ, Khan MA, Yoo ER, Cholankeril G, Kim D, Ahmed A. Clinical epidemiology and disease burden of nonalcoholic fatty liver disease. World J Gastroenterol. 2017;23(47):8263-8276.

14. Majumdar A, Misra P, Sharma S, Kant S, Krishnan A, Pandav CS. Prevalence of nonalcoholic fatty liver disease in an adult population in a rural community of Haryana, India. Indian J Public Health 2016;60(4):26-33.

15. Farrell GC. The liver and the waistline: Fifty years of growth. J Gastroenterol Hepatol. 2009;24(3):S105S118.

16. Novakovic T, Mekic M, Smilic L, et al. Anthropometric and biochemical characteristics of patients with nonalcoholic fatty liver diagnosed by non-invasive diagnostic methods. Med Arch. 2014;68(1):22-26.

17. Pardhe, B.D., Shakya, S., Bhetwal, A. et al. Metabolic syndrome and biochemical changes among nonalcoholic fatty liver disease patients attending a tertiary care hospital of Nepal. BMC Gastroenterol 2018;18(5):109-11.

18. Agarwal A, Jain V, Singla S, Baruah B, Arya V, Yadav R, et al. Prevalence of non-alcoholic fatty liver disease and its correlation with coronary risk factors in patients with type 2 diabetes. J Assoc Physicians India. 2011;59:35155.

19. Mahaling DU, Basavaraj MM, Bika AJ. Comparison of lipid profile in different grades of non-alcoholic fatty liver disease diagnosed on ultrasound. Asian Pac J Trop Biomed. 2013;3(11):907-12.

20. Agrawal R, Mishra S, Dixit VK, Rai S. Association of non-alcoholic fatty liver disorder with obesity. Indian J Prev Soc Med. 2009;40(6):126-129

21. von Tacer K, Rozman D. Nonalcoholic Fatty Liver Disease: Focus on Lipoprotein and Lipid Deregulation. Journal of Lipids. 2011:14.

22. Ginsberg HN, Zhang YL, Hernandez-Ono A. Regulation of plasma triglycerides in insulin resistance and diabetes. Archives of Medical Research. 2005;36(3):232-240.

23. Lúcia Farias de Azevedo Salgado A, de Carvalho L, Claudia Oliveira A, Nascimento dos Santos V, Gilberto Vieira J, Roberto Parise E. Insulin resistance index (HOMA-IR) in the differentiation of patients with non-alcoholic fatty liver disease and healthy individuals. Arq Gastroenterol. 2010;47(2):165-169.

Source of Support: Nil; Conflict of Interest: None

Submitted: 22-11-2019; Accepted: 06-12-2019; Published online: 31-12-2019 